\title{
Sediment Analysis of a Prehistoric Rockshelter: The Abri Pataud
}

\author{
WILLIAM R. FARRAND \\ Quaternary Research Laboratory, \\ Department of Geology and Mineralogy, \\ The University of Michigan, \\ Ann Arbor, Michigan 48104
}

Received November 14, 1972

\begin{abstract}
Rockshelter and cave-mouth deposits accumulate in specialized niches through the breakdown of the enclosing bedrock, the addition of windblown and fluvial sediment and, in the case of prehistoric sites, human habitation debris. Certain modifications of routine sediment analysis are necessary in order to realize the full potential of paleoenvironmental interpretation. These sediments are coarse, necessitating the collection of large samples, commonly $10-20 \mathrm{~kg}$. The size and shape of the coarse fraction yields information on rockfalls, freeze-thaw activity, and weathering effects. Travertine and soil-carbonate coatings on the rock fragments indicate variations in ambient humidity and soil formation, respectively. Studies of the granulometry, mineralogy, and geochemistry of the fine fraction lead to conclusions concerning primarily the postdepositional modification of the sediments. Heavy minerals can be important in determining the provenience of the fine sediment. These methods of analysis are discussed in detail with the Abri Pataud as a specific example, and caution is urged in making regional generalizations from the study of a single site.
\end{abstract}

\section{INTRODUCTION}

Purpose. This paper is designed primarily as an introduction to an analytical method of dealing systematically and quantitatively with sediments found in prehistoric archaeological sites, especially those occurring in caves and rockshelters. This is a rather young discipline the use of which is expanding widely; it developed in western Europe only in the 1950 s, but its seeds had been planted just before the Second World War by R. Lais (1941). Its development and use have evolved greatly in the last $10 \mathrm{yr}$, almost exclusively in western and central Europe where regional or personal variations in methodology have sprung up (Bonifay, 1956; Lumley, 1969; Laville, 1964, 1971; Miskovsky, 1971-all in France; Schmid, 1958-in Switzerland; Brunnacker and Streit, 1967-in Germany; Vertes, 1959-in Hungary). Recently a 3-day symposium, held in Nice, France, was devoted entirely to this subject; this was organized by $\mathrm{H}$. de Lumley and the proceedings will be published in the Bulletin of the Association Française pour l'Etude du Quaternaire.

None of these basic works are available in English, although much abbreviated summaries of some of the methods can be found in English language works, e.g., by Schmid in Broth well and Higgs, 1969; in Butzer, 1971; and most recently by Bordes, 1972. Therefore, the purpose of this paper is to expose in some detail the techniques employed in such analysis and to discuss some of the more important interpretations that can be drawn from the resulting data. The methods discussed are derived primarily from the fundamentals laid down by Eugène Bonifay in his several publications beginning in 1952, and the Abri Pataud in France will serve as a specific example of analyses made and interpretations drawn. Limitations of space do not permit me, however, to enter into all the details of the sedimentological work (Farrand, in press) carried out at the Abri Pataud. The inter- 
ested reader will soon be able to consult the full account of the Harvard University excavations at that site, directed by H. L. Movius, Jr.

The Abri Pataud. The Abri Pataud, was, during the time it was occupied by prehistoric man, a rockshelter or abrisous-roche, that is, an undercut reentrant along the base of a bedrock cliff in which man or beast could find shelter from the elements by virtue of the overhanging bedrock roof. The Abri Pataud is located in the village of Les-Eyzies-de-Tayac (Dordogne), southwestern France and is situated along the base of south-southwestward facing limestone cliffs that border the floodplain of the Vézère River (Fig. 1).

The overhanging rock ledge that formed the Abri Pataud during Upper Paleolithic times apparently developed in a manner similar to the numerous rockshelters that presently exist along the Vézère valley, specifically by differential weathering of the bedrock. Once formed, a rockshelter will begin to accumulate a sedimentary fill, and under a climate similar to that of southwestern France during glacial times this fill will consist of limestone debris (éboulis) resulting from solution and frost weathering of the ceiling and walls, as well as of sediments brought in from outside the shelter by running water, the wind, or human beings. At the Abri Pataud the total average thickness of the strata is $8.8 \mathrm{~m}$ (Fig. 2) and its rate of accumulation was as great as 100-182 $\mathrm{cm} / 1000 \mathrm{yr}$ at times, although interruptions for soil-forming intervals reduce the overall average rate to $55 \mathrm{~cm} / 1000 \mathrm{yr}$ between 34,000 and 20,000 y. a. (Farrand, in press; Movius, 1972).

Stratigraphy. The stratigraphic succession in the Abri Pataud is given in Table 1 at the end of this article. Each archaeologically rich horizon has been designated a "level" and numbered serially from top to bottom of the section. The

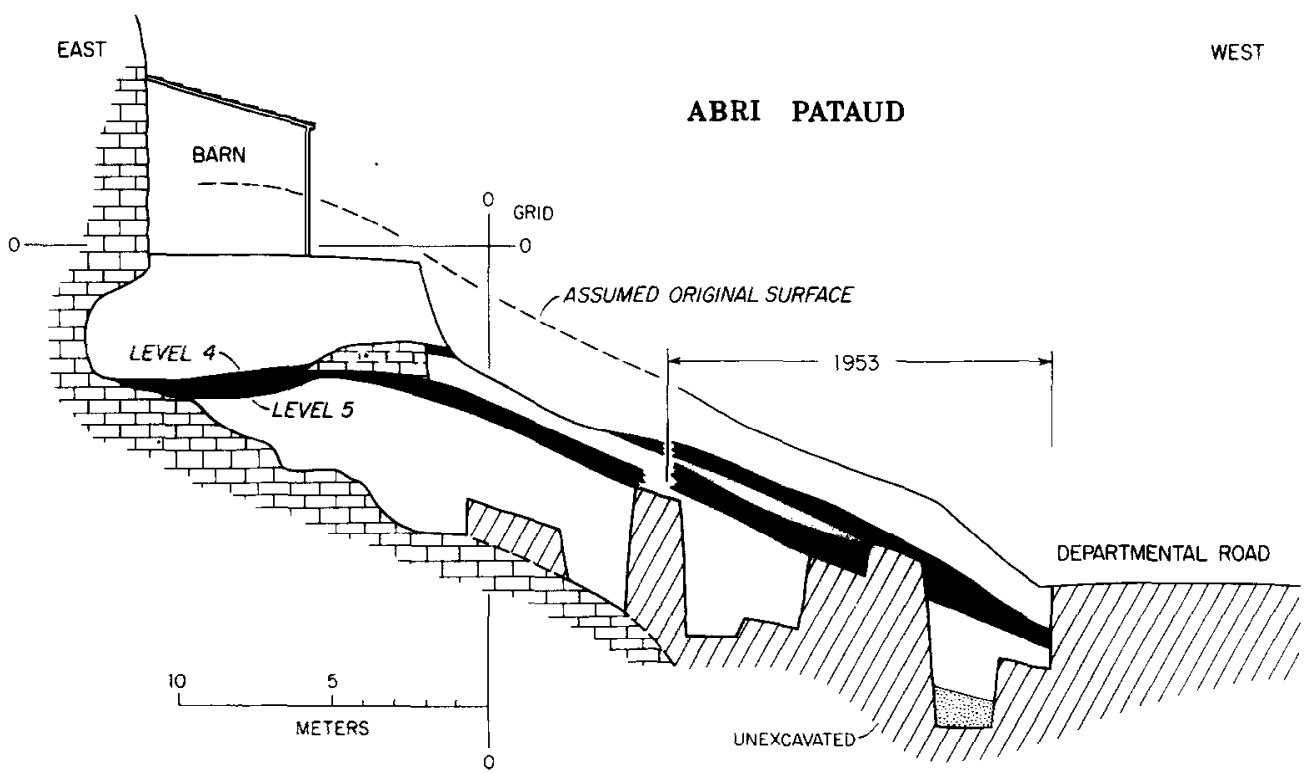

FIG. 1. Schematic profile east-west through the Abri Pataud. Only Levels 4 and 5 are shown; note that they dip both inward and outward from the area of large roof falls. Vézère sand (stipled) is exposed in the bottom of the 1953 trench at the same altitude as the surface of the modern Vézère floodplain, which is not shown but abuts the departmental road immediately to the west of this section. Note also that the bedrock floor of the abri rises in stepwise fashion toward the inner wall, each step representing a period of retreat of the back wall. The barn wall is artificially cut into the rock. 


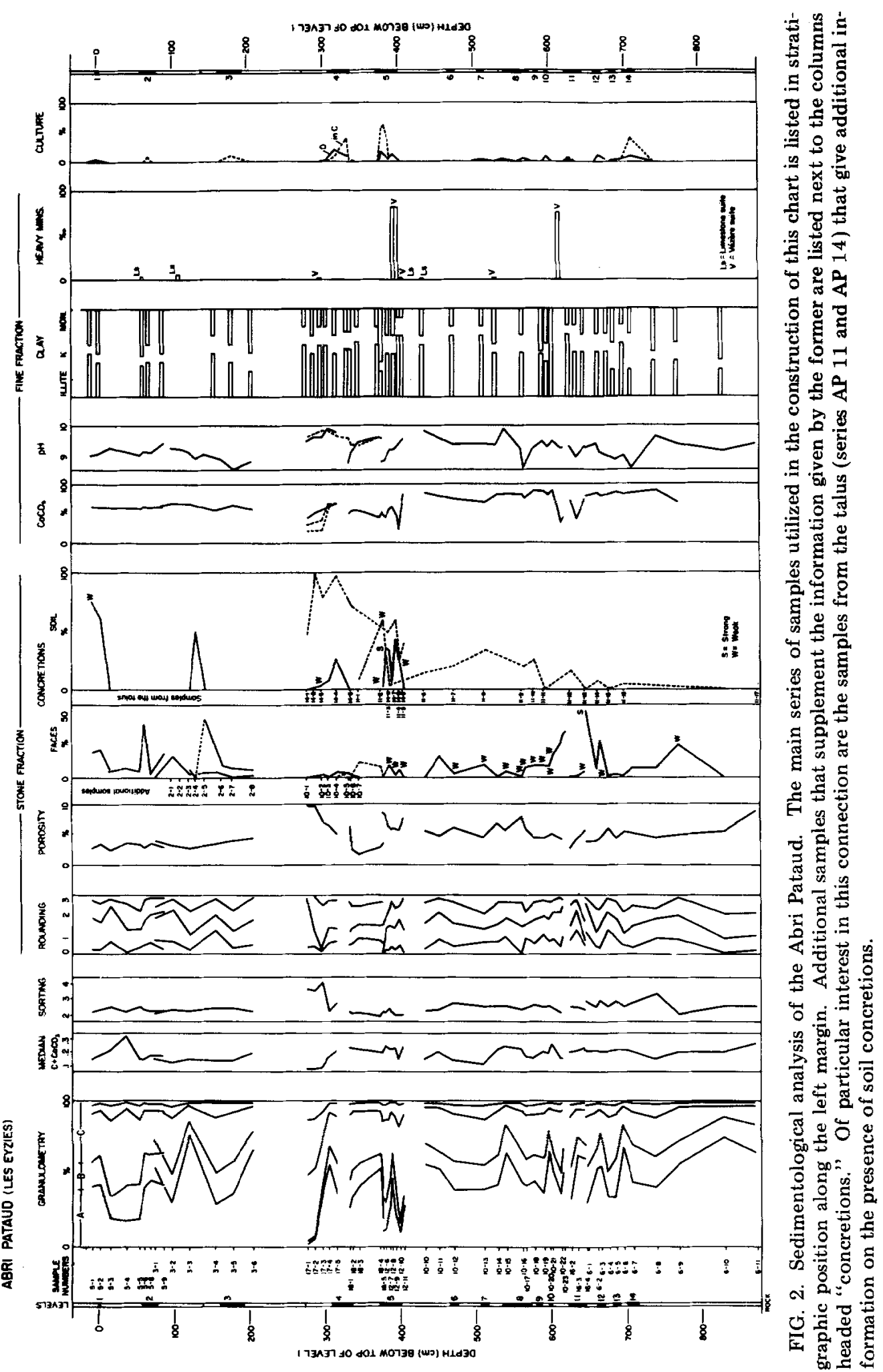


TABLE 1

Summary of climatic interpretation of Abri Pataud

\begin{tabular}{|c|c|c|c|}
\hline Unit & Culture & Climate & $\begin{array}{c}\text { Date (BP) } \\
\text { (Movius, 1972) }\end{array}$ \\
\hline $\begin{array}{l}0 / 1 \\
1 \\
1 / 2 \\
2 \\
2 / 3\end{array}$ & $\begin{array}{l}\text { Sterile } \\
\text { Lower Solutrean } \\
\text { Sterile } \\
\text { Protomagdalenian } \\
\text { Sterile }\end{array}$ & Cold, somewhat moist & 22,000 \\
\hline Soil on 3 & Sterile & Mild & \\
\hline $\begin{array}{l}3 \\
3 / 4: \text { Yellow }\end{array}$ & $\begin{array}{l}\text { Perigordian VI } \\
\text { Sterile }\end{array}$ & Cold, dry & 23,000 \\
\hline $3 / 4: \operatorname{Red}$ & Sterile & Warm, moist & \\
\hline $\begin{array}{l}4 \\
4 / 5\end{array}$ & $\begin{array}{l}\text { Noaillian } \\
\text { Sterile }\end{array}$ & Cool, somewhat moist & 27,000 \\
\hline 5 & Perigordian IV & Warm, moist & 28,150 \\
\hline $\begin{array}{l}5 / 6 \\
6 \\
6 / 7 \\
7 \\
7 / 8 \\
8 \\
8 / 9 \\
9 \\
9 / 10 \\
10\end{array}$ & $\begin{array}{l}\text { Sterile } \\
\text { Evolved Aurignacian } \\
\text { Sterile } \\
\text { Intermediate Aurignacian b } \\
\text { Sterile } \\
\text { Intermediate Aurignacian a } \\
\text { Sterile } \\
\text { Intermediate Aurignacian (?) } \\
\text { Sterile } \\
\text { Intermediate Aurignacian (?) }\end{array}$ & $\begin{array}{l}\text { Cold, somewhat moist } \\
(\text { not as cold as above } 3)\end{array}$ & 32,800 \\
\hline $\begin{array}{l}10 / 11 \\
11\end{array}$ & $\begin{array}{l}\text { Sterile } \\
\text { Early Aurignacian b }\end{array}$ & Mild, moist & 32,600 \\
\hline $\begin{array}{l}11 / 12 \\
12 \\
12 / 13 \\
13 \\
13 / 14 \\
14\end{array}$ & $\begin{array}{l}\text { Sterile } \\
\text { Early Aurignacian a } \\
\text { Sterile } \\
\text { Basal Aurignacian b } \\
\text { Sterile } \\
\text { Basal Aurignacian a }\end{array}$ & $\begin{array}{l}\text { Cold, with fluctuating } \\
\text { humidity }\end{array}$ & 33,260 \\
\hline
\end{tabular}

intervening relatively sterile units have been called "éboulis" and have been numbered with respect to the "levels" they separate. For example, Eboulis $2 / 3$ is the sterile horizon that separates the occupational Levels 2 and 3 . Certain horizons have been further subdivided, such as Eboulis 3/4:Red, Eboulis 3/4: Yellow, Eboulis 10/11:Wash, and so forth.

Geologically the filling of the Abri Pataud is relatively simple. With the exception of a fine-grained, dark reddishbrown layer (Eboulis 3/4:Red), the fill consists of limestone éboulis with greater or lesser additions of windblown (eolian) sand and of human occupational debris. The eolian component is volumetrically always a minor element, except in the base of Level 5, in Eboulis 10/11. Similarly, human occupational debris does not play an important role in determining the character of the sediments except in the cases of Levels, $2,3,4$, and 5 . In the other occupational horizons human debris is volumetrically a very minor component. Such a characterization, or simplification, of the sedimentary fill is in 
no way a denial of the presence of very real and important variations in the composition of the sediments, as we shall see.

\section{METHODS OF STUDY}

Geological study and more particularly sedimentological study played a very small role or none at all in the interpretation of prehistoric cave sites prior to the 1950s. Now techniques for the systematic study of cave and rockshelter sediments have been developed and they go hand-in-hand with more elaborate excavation methods currently employed. The general goal of such studies is an interpretation of the paleoenvironment, and specifically the paleoclimate, under which the cave or rockshelter deposits accumulated. It is desirable to have an independent source of information on paleoclimate because of complications in interpretations based on fossil floras and faunas. In caves inhabited by man the macroflora and macrofauna incorporated in the strata may have been strongly influenced by the habits and particularly the diet of the inhabitants; microflora (pollen) is lacking in many cases because of poor preservation; and the job of washing and screening for a large sample of microfauna may be rather time consuming. On the other hand, the sedimentary framework in which the artifacts are found is always present and has been found to be quite amenable to paleoclimatological interpretation in certain areas. If pollen and microfauna are also present, then there is the possibility of independent checks on the interpretation.

Paleoclimatic interpretation of the sediments is based on two groups of variables: (a) those concerning the character of the sediment as it originally accumulated, and (b) those concerning the changes, mainly weathering, undergone by the sediment since it was deposited. In extreme cases, the latter may completely mask the former, although in the usual case some aspects of the original sediment can be observed in spite of the changes imposed by weathering. In addition, both (a) and (b) may be conditioned by the presence of human habitation, and some estimate of the human influence must enter into the interpretation. In this study the parameters studied under category (a) are granulometry, degree of sorting, abundance of travertine concretions, heavy minerals, and the human input. In category (b) they are the abundance of clay-size fraction, variations in clay mineralogy (in part), rounding and porosity of the stone fraction, abundance of soil concretions, calcimetry, and $\mathrm{pH}$ of the fine fraction.

\section{Sampling}

Ideally geological sampling of the sediments should be done by the geologist simultaneously with the archaeological excavation. In practice this is often not possible, and samples must be taken from sections remaining after the conclusion of the excavation, as was the case for the majority of samples studied here.

Another complication in dealing with rockshelter and cave sediments is their coarseness. All sizes of rock debris from clay particles to rock fragments measuring several meters on a side may be included in a given stratum. There is nevertheless a practical limit to the size of rock fragments that can be taken to the laboratory. Bonifay (1956) chose a longest dimension of $10 \mathrm{~cm}$ as the upper limit of materials submitted to laboratory tests, and this arbitrary limit has been adopted by Laville (1964) and by us for this study. However, even this relatively small size limit imposes the necessity of taking relatively large samples, commonly $10-20 \mathrm{~kg}$, in order to assure an adequate statistical sample of the larger fragments.

At the Abri Pataud we collected 18 different series (columns) of samples, numbered AP 1 through AP 18 . Individual samples within each series are numbered consecutively from top to bot- 


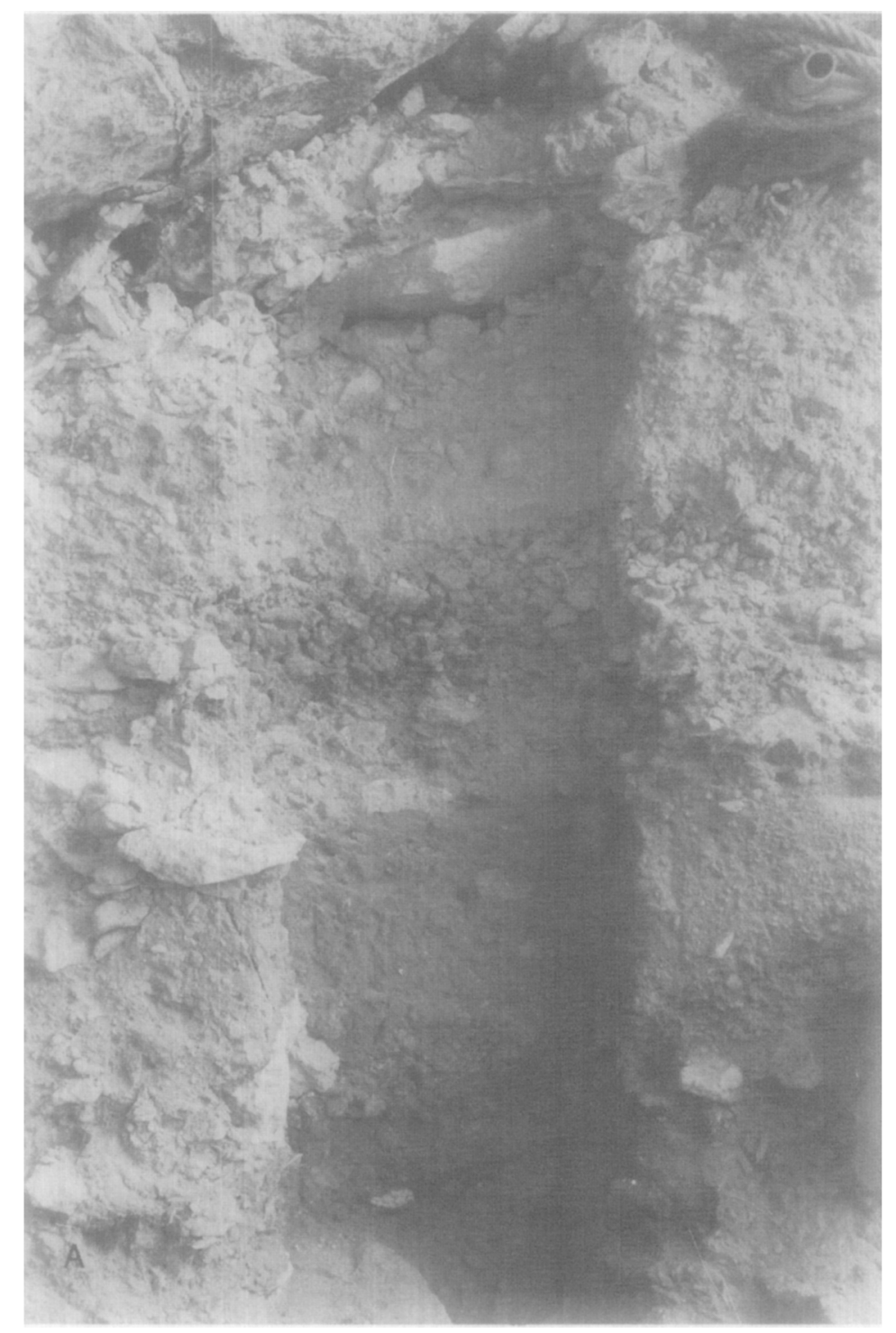

FIG. 3A. Typical sampling columns at the Abri Pataud: A. Column AP 2; bed of éboulis secs extends across middle of column. The width of each column shown is about $40-45 \mathrm{~cm}$. B. Column AP 3; C. Column AP 5. "Couche 1" is Level 1 (Early Solutrean).

tom of the sampling column, e.g., AP 5-1, AP 5-2, etc. The exact stratigraphic position of the various samples can be seen in Fig. 2. Typical sampling columns are shown in Fig. 3 . The thickness of an individual sample and the vertical interval between samples in a given column were dictated by the degree of vertical variation in the sediments apparent in the field. The sediment was loosened with a small pick and a brush, and care was taken not to break up the rock fragments in the process. All rock fragments within the sample area that were larger than $\mathbf{1 0}$ $\mathrm{cm}$ were noted, measured, and discarded.

\section{Field Analysis}

Preliminary treatment of the sample was effected in the field and consisted of the following steps:

a. The total sample ( $\leqslant 100 \mathrm{~mm}$ particle size) was spread out on a canvas or 


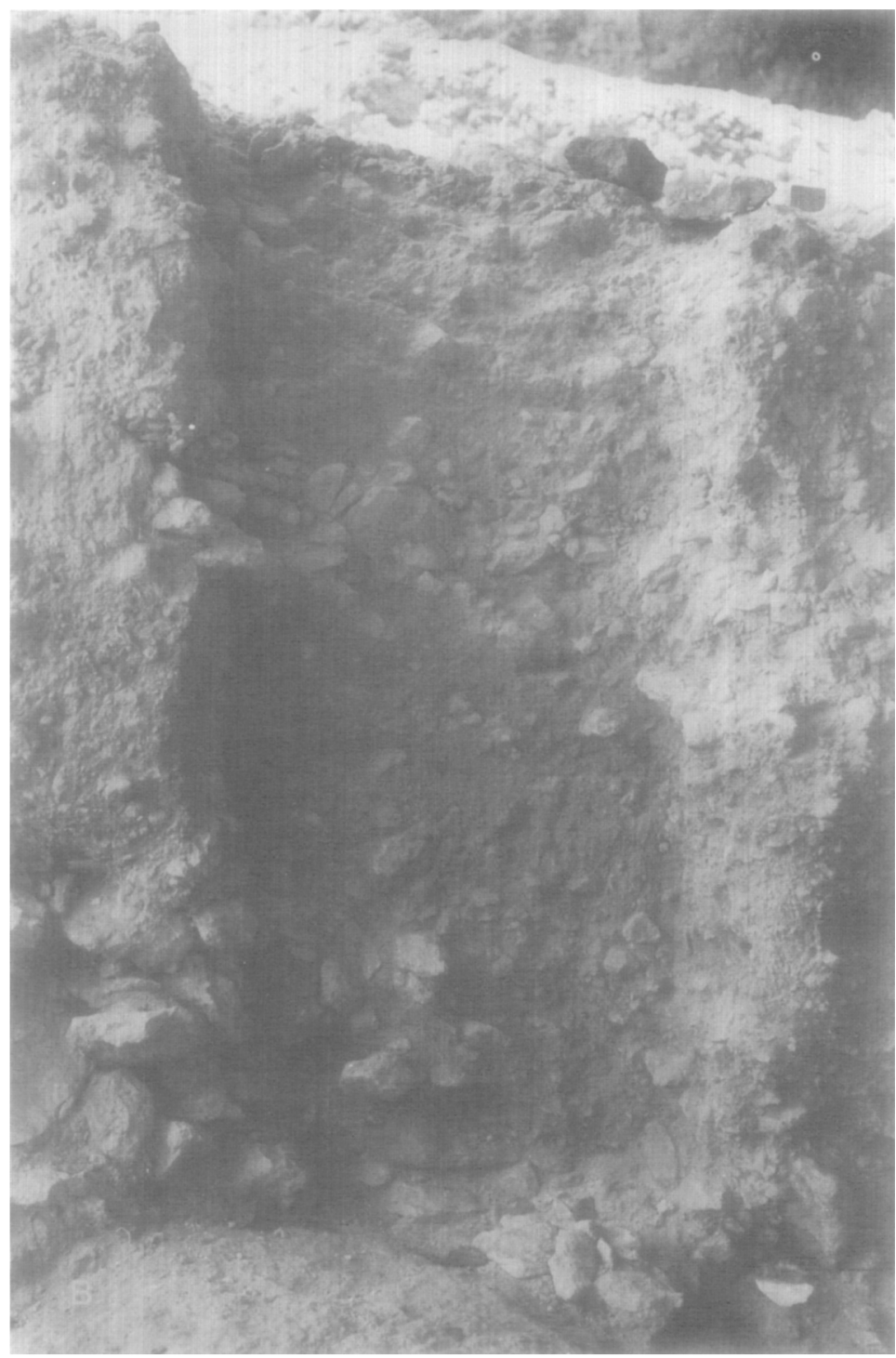

FIG. 3B

plastic sheet and allowed to dry in the Sun to a constant weight; any particular fragile bone fragments or flints were separated at this time; then the sample (including the fragile materials) was weighed.

b. The entire sample was then sieved dry through two nested 18-in.-diam sieves, one with a $10-\mathrm{mm}$ screen and the other with a $2-\mathrm{mm}$ screen; after collecting a 1- or 2-kg sample of the fraction finer than $2 \mathrm{~mm}$, we washed the material retained on the two sieves in order to remove any fines, especially clay, that ad- hered to the larger rock fragments; the material on the sieves was again dried and weighed; the result of this operation was to divide the total sample into three fractions: Fraction A, comprising sediment between 100 and $10 \mathrm{~mm}$, Fraction B, the sediment between 10 and $2 \mathrm{~mm}$, and Fraction $\mathrm{C}$, the sediment finer than 2 $\mathrm{mm}$.

c. At this point all the cultural debris (flint, bones, exotic stones, etc.) was separated from the $A$ fraction, weighed, and called Fraction D. The weight of Frac- 


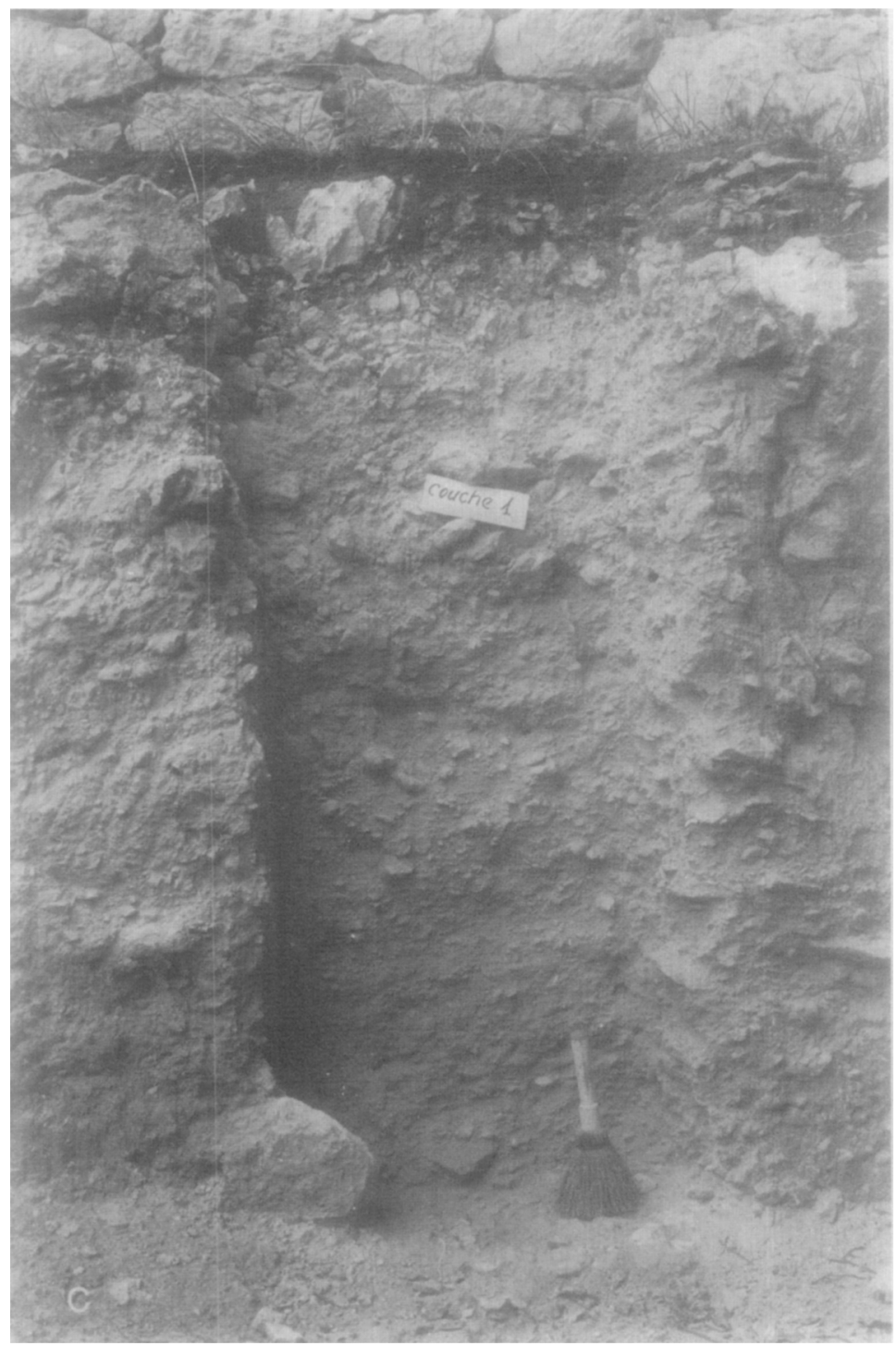

FIG. 3C

tion $\mathrm{D}$ was not included in the sum $\mathrm{A}+$ $\mathrm{B}+\mathrm{C}$.

Thus, immediately in the field one can obtain a preliminary analysis of the overall granulometry of the rockshelter sediments; this is shown in the far left (A, $\mathrm{B}$, and $\mathrm{C}$ fractions) and far right ( $\mathrm{D}$ fraction) columns of Fig. 2.

\section{Laboratory Analysis}

Granulometry. In the laboratory a number of studies were conducted on both the A fraction (rock fragments) and the $\mathrm{C}$ fraction (fines). The $\mathrm{B}$ fraction, which consists primarily of small limestone fragments between 10 and $2 \mathrm{~mm}$, was not studied in detail because the small size of the fragments makes them difficult to manipulate. The $\mathrm{B}$ fraction enters into the granulometric analysis only. For our purposes the total A+B fraction has been subdivided as follows ${ }^{1}$ :

${ }^{1} \mathrm{Phi}$ units are a convenient logarithmic transformation of the Wentworth grade scale based on the relation $\log d=-\phi(\log 2)$, where $d$ is the grain diameter. 


$$
\begin{aligned}
2-4 \mathrm{~mm} & =-1 \text { to }-2 \phi \\
4-8 & =-2 \text { to }-3 \\
8-16 & =-3 \text { to }-4 \\
16-32 & =-4 \text { to }-5 \\
32-64 & =-5 \text { to }-6 \\
64-96 & =-6 \text { to }-6.5
\end{aligned}
$$

This is a slight deviation from the Bonifay method, but is considered preferable in order to display the data in statistically valid form, for example, the histograms in Fig. 5. For future studies, it is suggested that $128 \mathrm{~mm}(-7 \phi)$ instead of 100 $\mathrm{mm}$ be used as the upper limit for stone fragments collected for laboratory analysis, and that field sieving be carried out with screens of $16 \mathrm{~mm}(-4 \phi)$ or $8 \mathrm{~mm}$ $(-3 \phi)$ and $2 \mathrm{~mm}(-1 \phi)$. This will eliminate the limits of 100 and $10 \mathrm{~mm}$, which fall at awkward intervals on the phi scale.

Roundness. Next, the stones in each size class of each sample were evaluated for roundness. Roundness in general terms refers to the degree of blunting of originally angular edges of a rock fragment and is independent of the overall shape of the fragment. The scale of roundness goes from very angular to very well rounded. It was decided to divide the rock fragments simply into four roundness classes by visual inspection (see Fig. 4) in a manner similar to the Power's roundness scale (see Folk, 1968, p. 11). First, the end members of the roundness spectrum were isolated, namely, those fragments with only angular corners (Class 0 ) and those fragments with only rounded corners (Class.3). The remaining fragments were separated into intermediate categories, those fragments with more angular corners than rounded comers (Class 1) and those fragments with more rounded comers than angular ones (Class 2). Reproducibility of roundness determinations under this system was evaluated by repeated determinations on the same sample by the same person and by different persons and found to be satisfactory. The class number assigned to each category may be used in the calculation of a roundness index, as done by Bonifay (1956), but it was found that a single numerical value masked some of the information that could be shown in graphical form, as in Fig. 2.

Porosity. The porosity of rock fragments in each sample was also measured, once again using a method of Bonifay (1956) that consists of immersing dry rock fragments in water until saturated (usually $2 \mathrm{hr}$ ), weighing them while saturated and then weighing them once again after drying to constant weight. Porosity was measured systematically on all fragments between 30 and $50 \mathrm{~mm}$ diam in all samples in order to limit the sample to a size range abundantly represented in all the samples. Porosity throughout the Abri Pataud section has a range of values lying between 1 and $10 \%$ by weight (Fig. 2).

Concretions. The rock fragments were also inspected for traces of concretionary coatings. Two kinds of such coatings were found: (a) a travertine-like concretionary layer formed on the limestone fragments before they were completely detached from the bedrock wall and (b) a chalky soil carbonate that formed on the fragments after they had become part of the sedimentary fill on the floor of the abri. The former could be recognized by its smooth or mamillary surface, slightly more pinkish or orange in color than the limestone itself. In most cases this travertine formed only a very thin film (less than a millimeter thick), but in a few cases it was distinctly more prominent (e.g., AP 5-6, AP 10-23, AP 6-1). In all cases where present it was strictly limited to one face of a rock fragment, and on that face it terminated abruptly at the freshly broken edges. Furthermore, on certain fragments one face, weathered and somewhat rounded, could be identified as part of the former surface of the bedrock wall and the opposite face, bounded by fresh, angular edges, identi- 

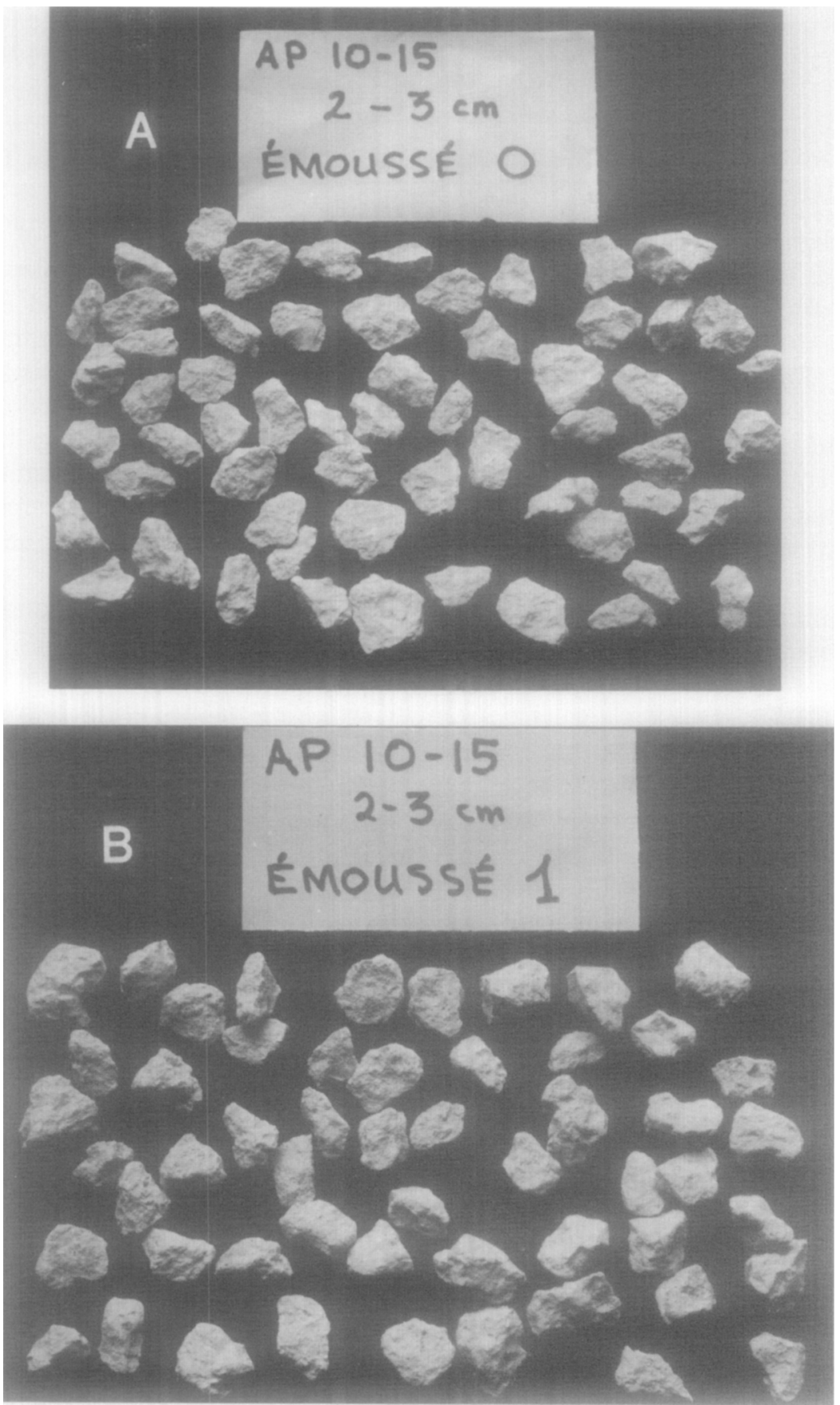

FIG. 4A, B. Example of Roundness categories (émoussé = rounded) utilized in the Abri Pataud study. The four photographs together include all the stones between 2 and $3 \mathrm{~cm}$ long in sample AP 10-15.

fied as the fracture along which the fragment was detached from the wall. Travertine concretions were found exclusively on the freshly fractured face. These observations constitute the major argument for the hypothesis that this type of con- 

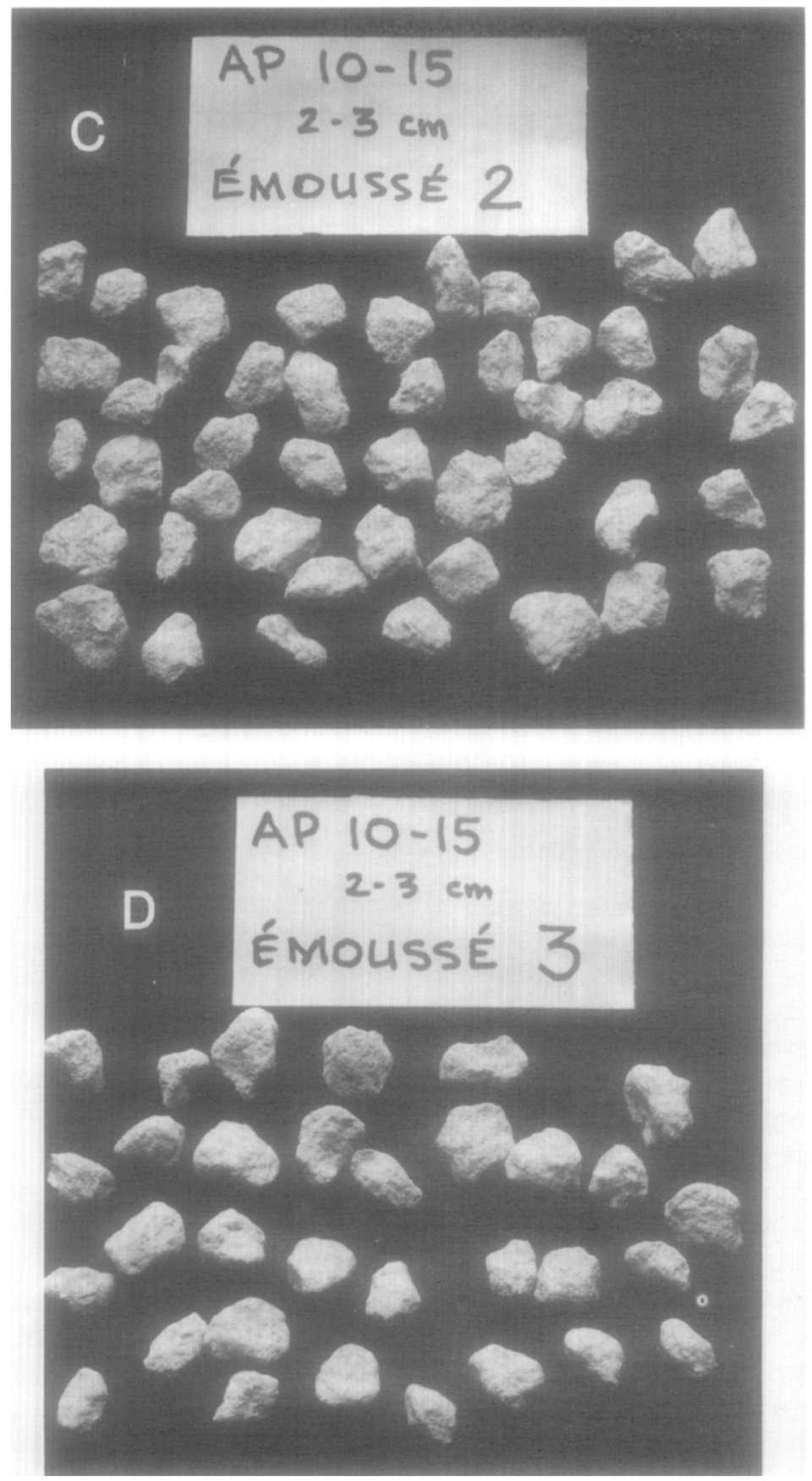

FIG. 4C, D

cretion formed in a crack in the bedrock wall prior to the fragment being detached completely from the bedrock. Such con- cretions are equivalent to the concrétions $p$ (= paroi) of Bonifay (1956).

The soil concretions, the second type 

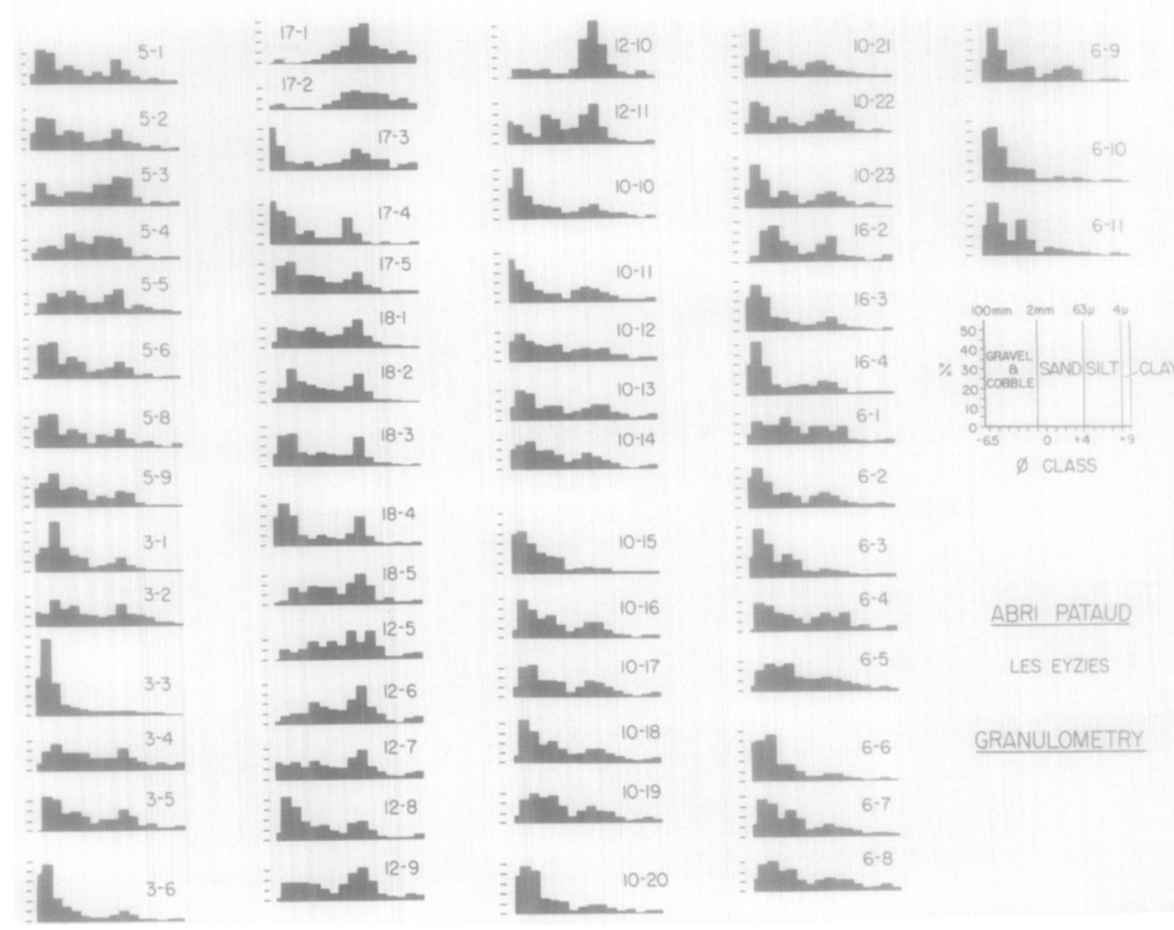

FIG. 5. Histograms of particle-size distribution at the Abri Pataud. All bars represent one phi interval except the bar at the far left, which is only one-half phi in width. The histograms are arranged in stratigraphic order from AP 5-1 (top left) to AP 6-11 (bottom right).

mentioned above, consisted of chalky white or dense, dull grayish-white carbonate forming a discontinuous coating on one or several faces of a rock fragment. In cases where this kind of concretion was rather heavy, it generally cemented together sand and silt grains from the sedimentary matrix, and thus had a granular and dirty appearance. On the other hand, on those rock fragments on which this type of concretion was weakly developed it commonly took the form of chalky dendritic patterns apparently related to plant rootlets. This type of concretion is similar to that called concrétions $s(=s o l)$ by Bonifay (1956), and because of its correlation with other evidence of weathering as well as its similarity to secondary soil carbonate (e.g., in a Cca horizon) it is considered to mark the presence of a pedogenic horizon within the sediments.

Fine Fraction. The $\mathrm{C}$ fraction (less than $2 \mathrm{~mm}$ diam) was also submitted to a number of tests. The overall granulometry of the total sample, including the $\mathrm{C}$ fraction, is shown by means of histograms at one phi intervals in Fig. 5 and in Fig. 2 (column at the far left). ${ }^{2}$ For the nondecalcified $\mathrm{C}$ fraction, the median and the degree of sorting (Trask's coefficient) are given in the second and third columns from the left in Fig. 2.

Chemical analysis of the $\mathrm{C}$ fraction consisted of spectrographic analysis of the major elements, determination of the component soluble in hydrochloric acid ("carbonate-equivalent"), and measurement of pH. The results of the latter two determinations are given in Fig. 2.

The principal interest in the major element analysis lies in the determination of total $\mathrm{SiO}_{2}, \mathrm{Al}_{2} \mathrm{O}_{3}, \mathrm{Fe}_{2} \mathrm{O}_{3}$, and $\mathrm{CaO}$ both ${ }^{2}$ Note that the different upper limits for the
clay-size fraction have been shown; total clay
$(<0.0039 \mathrm{~mm}$ on Wentworth scale $)$ is given in
Fig. 5 , but only fine clay $(<0.002 \mathrm{~mm})$ in Fig. 2. 
because they constitute the bulk of each sample (90-100\%) and because they are the major rock-forming components in the limestone bedrock of the region. The $\mathrm{SiO}_{2}, \mathrm{Al}_{2} \mathrm{O}_{3}$, and $\mathrm{Fe}_{2} \mathrm{O}_{3}$ increased severalfold in all beds that seemed to have undergone weathering. These variations can be explained simply as the result of greater or lesser decalcification of éboulis that originally had approximately the same chemical composition throughout the section. This relationship is shown in Fig. 6. The "clay mineral," $\mathrm{SiO}_{2}$ and $\mathrm{Fe}_{2} \mathrm{O}_{3}$ do increase in the weathered horizons relative to the $\mathrm{CaCO}_{3}$-content of these horizons, but there is no absolute increase in these components.

Calcium Carbonate and $\mathrm{pH} . \mathrm{CaCO}_{3}$ equivalent and $\mathrm{pH}$ were measured on the fine fraction of all the samples. The $\mathrm{CaCO}_{3}$-equivalent was determined by re-

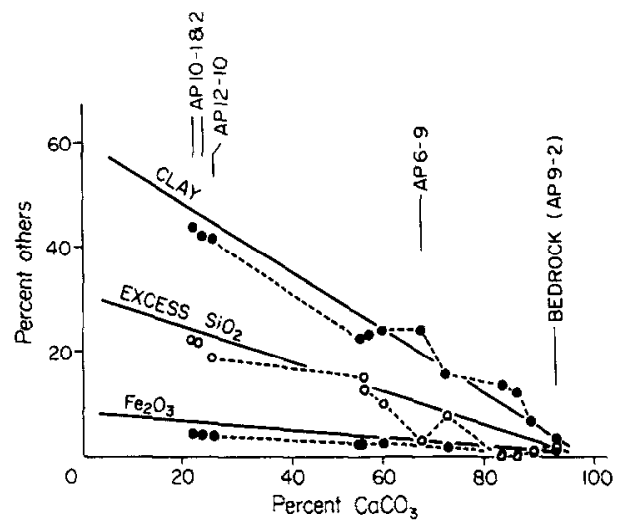

FIG. 6. Progressive change in mineralogy of éboulis samples through weathering. Solid straight lines show the calculated change that would be produced by the simple decalcification of bedrock, specifically sample AP 9-2. The major elements are grouped as "clay mineral" $\left(\mathrm{Al}_{2} \mathrm{O}_{3}+\mathrm{SiO}_{2}\right.$ in the ratio $\left.1 / 3\right)$, "excess $\mathrm{SiO}_{2}$ " (essentially quartz) which is the total $\mathrm{SiO}_{2}$ in a given sample less than the $\mathrm{SiO}_{2}$ used in the calculation of "clay mineral," and " $\mathrm{Fe}_{2} \mathrm{O}_{3}$." The percentages of these compounds are plotted against the percentage of $\mathrm{CaCO}_{3}$ in each sample. The points show the actual analyses of éboulis samples from the abri sediments. The scatter of the points is apparently due to minor variations in the composition of the bedrock and to the removal of some of the weathering products by ground water. acting a representative sample of sediment finer than $0.125 \mathrm{~mm}$ diam with $\mathrm{HCl}$ until reaction ceased. This size fraction only was analyzed in the interests of economy of time and materials since it has been shown for similar nearby deposits that nearly all the variation in calcimetry is explained by variation in the finer part of the $\mathrm{C}$ fraction (Laville, 1964 , p. 44). However, this is a generalization that cannot be widely applied without additional verification. The values of " $\mathrm{CaCO}_{3}$-equivalent" range from about $90 \%$ (in the lower half of the section) to near $20 \%$ in the most strongly weathered layers (Eboulis 3/4: Red and Level 5-base).

The $\mathrm{pH}$ of a slurry of the total $\mathrm{C}$ fraction in distilled water was determined by means of a $\mathrm{pH}$ meter. The $\mathrm{pH}$ values, which range between 8.5 and 10 , show very little agreement with the $\mathrm{CaCO}_{3}$ values (see Fig. 2). However, an evaluation of the interrelationships of $\mathrm{CaCO}_{3}$, $\mathrm{pH}$, intensity of habitation and of weathering (Farrand, in press) showed several important relations that can be summarized only briefly here. Rather clearly there is no systematic difference in $\mathrm{CaCO}_{3}$-content between habitation levels and sterile éboulis; high and low values are found in both. Secondly, there is a distinct tendency for habitation levels to show a more acid $\mathrm{pH}$ than that found in the éboulis. Seven out of eight samples with $\mathrm{pH}<8.9$ come from occupation levels, whereas only 3 of 17 samples with $\mathrm{pH}>9.4$ are from occupation levels. Thus, it seems warranted to suggest that human wastes and garbage tend to produce more acid conditions in the sediments of habitation levels. Thirdly, samples that come from weathered layers or from layers with concretionary soil carbonate exhibit a distinctly lower percentage of $\mathrm{CaCO}_{3}$ than layers that are lacking in indicators of postsedimentary alteration (Fig. 2). Samples with indicators of weathering or soil carbonate ac- 
count for 23 out of 31 samples with less than $66 \% \mathrm{CaCO}_{3}$. In contrast, only 2 samples out of 28 with more than $65 \%$ $\mathrm{CaCO}_{3}$ show any obvious signs of alteration, and in both cases (Sample AP 17-5 and 6-1) it is a question of soil carbonate that may have simply been translocated from overlying horizons and thus may not reflect weathering in situ.

Therefore, one can draw the conclusions that (a) human occupational layers tend to have relatively low $\mathrm{pH}$ values and (b) weathered layers tend to have reduced $\mathrm{CaCO}_{3}$ values. However, since there is a fairly large overlap in the $\mathrm{pH}$ ranges, the first generalization cannot be applied indiscriminately; a fairly large number of samples is necessary for its correct application. The second conclusion seems more decisive and easier to apply, although there is a little overlap with values from unweathered layers. Unfortunately these generalizations are not mutually exclusive.

\section{Mineralogical Studies}

Clay Minerals. The clay minerals and heavy minerals in the $\mathrm{C}$ fraction of the
Abri Pataud sediments were identified by two French laboratories specializing in these subjects. The clay minerals were identified by Mlle Hélène Paquet in the laboratory of Professor Georges Millot at Strasbourg. The three major families of clay minerals in the fraction finer than $0.002 \mathrm{~mm}$ have been identified, and their abundance relative to total clay minerals has been estimated to the nearest $10 \%$ (third column from the right in Fig. 2 where "Mon" is montmorillonite and "Kc" is kaolinite with perhaps minor quantities of chlorite). Kaolinite is in general the least abundant and the least variable of the three mineral groups. The average abundance and variation in 60 samples of sediment and bedrock are as follows:

\begin{tabular}{lcc}
\multicolumn{1}{c}{ Mineral } & $\begin{array}{c}\text { Average } \\
\text { abundance }\end{array}$ & $1 \mathrm{Sd} \mathrm{d}$ \\
Kaolinite & $18.2 \%$ & $\pm 7.4 \%$ \\
Illite & 50.3 & \pm 13.6 \\
Montmorillonite & 31.1 & \pm 16.5
\end{tabular}

In detail, wherever there is an increase in illite, there is a concomitant decrease in montmorillonite, the value of kaolinite

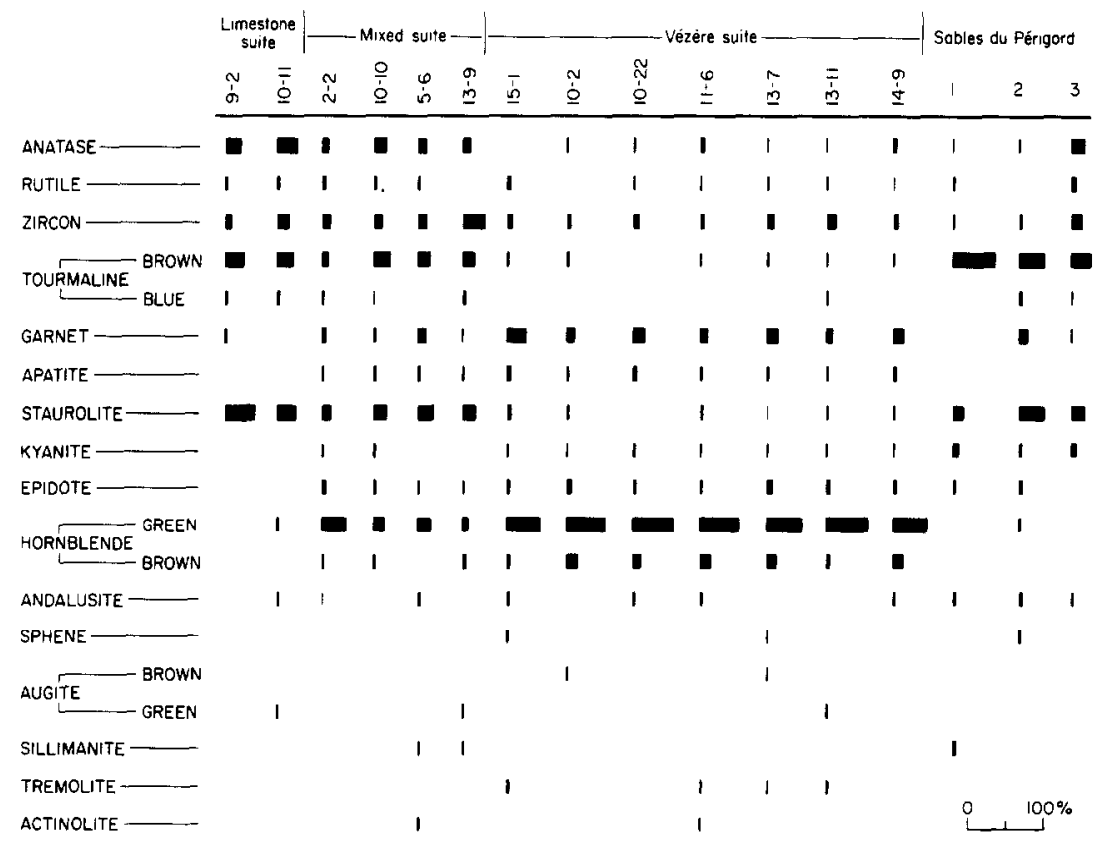

FIG. 7. Histograms of heavy mineral distributions in Abri Pataud sediments, Vézère sand, the local bedrock, and the sables du Périgord. The determinations, by Madame M. Ters, Paris, were made on the 50- to $500-\mu \mathrm{m}$ fraction of the sediments. 
being almost constant from sample to sample. Under the humid, temperate climate of western Europe-both now and during the last glaciation-montmorillonite is the clay mineral most susceptible to weathering, and kaolinite is the least susceptible (Millot, 1964, pp. 127-128). Therefore, on the basis of clay minerals alone, beds with relatively high values of montmorillonite and low values of illite (less than $40 \%$ ) can be interpreted as having undergone little or no weathering, and vice versa. The limestone that gave rise to the bulk of these sediments contains $40 \%$ montmorillonite, 40-60\% illite, and 0-20\% kaolinite.

Heavy minerals. The heavy minerals in the Abri Pataud sediments were studied by Madame Mireille Ters in Paris; the fraction between 50 and $500 \mu \mathrm{m}$ was examined and the results are presented in Fig. 7. The 16 samples represent typical sediments from the abri as well as of limestone bedrock, fluvial sand from the Vézère floodplain, the Sables du Périgord. (The latter are residual sands of Eocene age that cover much of the limestone plateaus in the Périgord region.) The samples could be separated into three groups on the basis of their heavy mineral suites. The first group is characterized by relatively high amounts of anatase, zircon, tourmaline, and staurolite; the second group contains abundant hornblende and garnet and very little of the first four mentioned minerals; the third group is intermediate, having a mixture of those minerals characterizing the first two suites.

The essential problem to be attacked by the study of the heavy minerals was not one of paleoclimate; but of the provenience of the sandy matrix of the abri sediment. Certain strata, notably the basal part of Level 5 and Eboulis $5 / 6$, are conspicuously sandy, the sand being composed predominantly of quartz and mica. The limestone bedrock is also rather sandy, both quartz and mica being quite conspicuous in hand specimens. Therefore, it was first proposed that the sandy matrix between the limestone fragments was simply the product of disintegration by freeze-thaw and by solution of the limestone.

However, in spite of this superficial similarity between the sand originating from the disintegration of the bedrock and that found in the éboulis, heavy mineral analysis showed a preponderance of hornblende in certain samples, and it is extremely unlikely that great quantities of hornblende could have come from the limestone. On the other hand, the Vézère sand is rich in hornblende and garnet.

The clear opposition of the heavy mineral suites of the bedrock and of the Vézère sand facilitates the interpretation of provenience considerably. The Vézère suite (Fig. 7) is represented by AP 15-1 (floodplain sand) and six samples nearly identical to it. The sandy matrix of those samples must have been derived in large part from the Vézère floodplain, apparently by wind transport since there is no evidence of the action of running water in the abri. The limestone suite is characterized by the two bedrock samples, AP 9-2, and AP 10-11, and it is approximated by four sediment samples (AP 2-2, 10-10, 5-6, and 13-9). However, these latter four samples appear to be mixtures of the Vézère suite and of the pure limestone suite. They contain the four minerals that dominate the limestone, but also a moderate amount of hornblende and some garnet that could not have come from the limestone. Thus, we can speak also of a mixed suite of heavy minerals.

Therefore, one can conclude that the sandy sediments represented by samples labeled "Vézère suite" (Fig. 7) were derived predominantly from the Vézère floodplain by wind action. On the other hand, the other four "mixed" samples represent sandy sediments derived primarily from disintegration of the bedrock but containing some contribution of sand blown from the floodplain. No sample of éboulis matrix that was analyzed 
shows a heavy mineral suite that could have been derived exclusively from the limestone bedrock. Thus one can conclude that eolian activity was continuously present, but that its intensity varied considerably with time.

\section{DISCUSSION OF THE RESULTS}

\section{Presentation of Results}

The results of the analyses discussed are displayed primarily in the form of a chart (Fig. 2) on which the variation of each parameter is plotted with respect to its stratigraphic position in the site. In this manner one can readily observe the simultaneous changes in the character of the sediments as a function of time. The stratigraphic variation of the detailed granulometry is given in Fig. 5 .

\section{Formation of the Abri Sediments}

In the absence of any indication of the activity of running water within the Abri Pataud sediments, the sources of the sedimentary fill are threefold:

(a) break-up of the surrounding bedrock

(b) windblown debris

(c) debris introduced by the human inhabitants.

Volumetrically, the first of these is by far the most important; the second is an important contributor to the sandy matrix of certain strata and perhaps played at least a minor role in the buildup of all strata; the third type of debris is volumetrically unimportant except in certain rich occupational horizons.

Human Debris. Treating these three sources of sediment in inverse order, it is easy to see that human occupational debris can be readily identified. Its presence is, after all, the reason for the excavation in the first place. Human bones, flint tools and chipping debris, exotic stones (mainly quartz and quartzite pebbles from the Vézère), and art work (engravings and painting) are obviously the result of habitation of the abri. The re- mains of bones of large animals may or may not have been brought in by the human inhabitants. However, the fact that they are found nearly exclusively in the occupational levels suggests strongly that the bones were introduced by man. In terms of our sedimentological study the occupational debris in the $100-10 \mathrm{~mm}$ fraction of our samples was called the "D fraction," and its abundance has been plotted in the extreme right column of Fig. 2. The D fraction, however, is not a very reliable guide to the intensity of habitation. The living area at any given time in the past was not uniformly distributed over the area that was excavated. Moreover, the sampling columns were so chosen as to avoid the richest parts of the occupational layers since our emphasis is on the character of the natural sediments. Therefore, it is very unlikely that the $D$ fractions of the various samples represent comparable parts of the living areas.

A more reliable estimate of the intensity of habitation is the abundance of cultural debris in the $\mathrm{C}$ fraction of the samples, although we are dealing with the same samples and thus the same limitations mentioned. Nevertheless, statistically there is a greater likelihood that the quantity of small chips and fragments of bone and flint in the $C$ fraction will be more representative of the intensity of habitation than will be a handful of larger flints and bones in the A fraction, especially for the less rich habitations. For example, the presence or absence of a single large flint fragment can make a great difference in the weight percentage of the $\mathrm{D}$ fraction, whereas a few small flakes more or less in the $C$ fraction will have but little influence on the percentage. An estimate of the cultural debris in the $\mathrm{C}$ fraction is also included in the column headed "Culture" in Fig. 2.

Both types of estimates show the relatively great intensity of habitation in Levels 4 and 5, as well as in Level 14. Without doubt, the values shown for 
Levels 2 and 3 are considerably underestimated because the samples shown here were taken a good distance away from the main concentration of cultural debris in those horizons. The "Culture" column of Fig. 2 should be interpreted very conservatively, and perhaps simply in terms of the presence or absence of cultural debris in a given sample.

Eolian Sediment. Sediment blown by the wind from the Vézère floodplain into the Abri Pataud must have been limited to fine sand and silt sizes. There are the sizes most easily transported by the wind, and these are the sizes of sediment found in the floodplain (samples AP 15-1 and 15-2). The problem of separating the eolian and the limestone components of the éboulis matrix cannot be resolved, however, in terms of the grain-size distributions. Although the Vézère sand is somewhat less well sorted than the insoluble residue of the limestone, it does fall into the same size class, mainly between 0.25 and $0.063 \mathrm{~mm}$ (Fig. 8B). Arguments based on the heavy mineral suites discussed are more decisive; in certain strata the sandy matrix must have come predominantly from the floodplain, e.g., Eboulis 3/4:Red and the base of Level 5. The sandy matrix of other strata shows varying degrees of mixture of the Vézère and the limestone heavy mineral suites.

Bedrock Contribution. The contribution of the limestone bedrock to the Abri Pataud fill is in part extremely obvious and in part a question of interpretation. It is certainly obvious that large sections of the former bedrock roof collapsed and became incorporated into the sediments. Furthermore, all the rock fragments in the éboulis, with the exception of the volumetrically rare river stones brought in by man, are of limestone of the same kind as that composing the roof and walls of the abri. Thus, there can be no question about the source of the rock fragments. The source of the fine sedi-

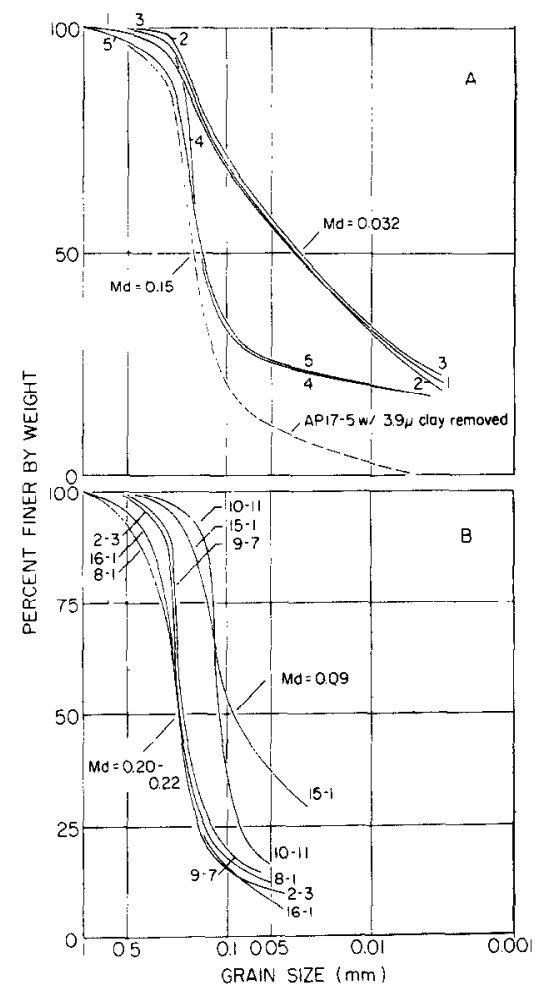

FIG. 8. Cumulative granulometric curves of decalcified sediment at the Abri Pataud. A (above). Decalcified sediments from the AP 17 series showing the effects of weathering. Note the poor degree of sorting and especially the increase in the abundance of clay-size particles in samples AP $17-1,2$, and 3 relative to AP 17-4 and 5 . Dashed curve shows similarity between these curves and those in 11B. B (below). Decalcified bedrock. (Samples 2-3, 10-11, and 16-1), modern éboulis ( $8-1$ ), sand from the barn wall (9-7) and Vézère sand (15-1). The Vézère sand has a distinctly different granulometry, and bedrock $10-11$ is definitely finer than the other rock samples, although just as well sorted.

mentary matrix that fills the spaces between the rocks is another question, and we have already seen that the study of the heavy mineral fraction reveals that there has been a considerable contribution of sand blown from the floodplain in certain strata, and probably at least a minor contribution to all strata. However, the sandy matrix of the unweathered strata in the abri with as much as 60-90\% carbonate must have been derived principally from the limestone be- 
cause the Vézère sand contains only $2-6 \% \mathrm{CaCO}_{3}$. Further arguments against a floodplain origin for the bulk of the sediment in the Abri Pataud are the smaller median grain size (Fig. 8B) and the color of the Vézère sand, a dark reddish brown (5 YR $3 / 4$, moist), in contrast to the very pale yellow $(2.5 \mathrm{Y} 8 / 6$, moist) of the bulk of the unweathered éboulis in the abri.

It can, therefore, be concluded that the vast majority of the matrix of the Abri Pataud éboulis came from the disintegration of the local bedrock. Only those strata with an overwhelming Vézère-like heavy mineral suite and a reddish brown color should be considered as sediments strongly influenced by wind-transported Vézère sand, specifically, Eboulis 3/4: Red, the basal layers of Level 5, and Eboulis 10/11:Wash.

From the point of view of paleoclimatology, it is interesting to ask the question whether limestone éboulis such as that filling the Abri Pataud is still forming today. The present-day rockshelters along the Vézère valley do not seem to be accumulating rock fragments on their floors, but this may be a misleading observation since it is not known in many cases to what extent these rockshelters have been cleaned out by the local people in very recent times. On the other hand, in the smaller niches that extend more or less horizontally along the limestone cliffs and that have not yet developed into full-sized rockshelters, one can observe spalling of the rock face and the accumulation of the spalls on the adjacent ledge. When this spall debris first forms it is much more tabular than the rock fragments found in the abri sediments, but after exposure for a few years on the ledge the fragments break down into more nearly equidimensional pieces, resembling very closely the smaller rock fragments of the Würm-age éboulis. Moreover, these rock fragments are rather angular. On the other hand, rock frag- ments fist-size or larger are rare in the modern accumulation.

The mechanism that produces this spalling is not yet clearly demonstrated. Although the rock fragments in the abri are attributed principally to freeze-thaw action, the occurrence of spalling in areas of seeping water and vegetation on the cliff face suggests the possibility of wetting and drying of the limestone face as a mechanism that encourages spalling. Furthermore, freezing temperatures are rather uncommon under the present climate of the Vézère valley.

Measurement of the rate of accumulation of the presently forming 'éboulis was begun by the late John P. Miller and is being continued by the present writer, but a definitive study of the processes currently operating on such a cliff face under the present climate remains to be done.

\section{Variation Within the Primary Sediments}

General. The parameters considered of major importance in characterizing the original, unweathered sediments in the Abri Pataud are (a) the size and abundance of rock fragments, i.e., the $A+B$ fraction, (b) the size and degree of sorting of the fine, or $\mathrm{C}$ fraction, (c) the heavy mineral composition of the $\mathrm{C}$ fraction, and (d) the presence and abundance of travertine concretions. The original sediments are also characterized by certain other parameters shown on Fig. 2, such as the $\mathrm{CaCO}_{3}$ content and clay mineral composition, but these parameters are best discussed in terms of the postdepositional changes that they have undergone (see next section).

The abundance of rock fragments $(\mathrm{A}+$ $B$ fraction) in the éboulis is shown in Fig. 2, and their size distribution is shown by the six bars at the left in each histogram in Fig. 5. In general, the percentage of $\mathrm{A}+\mathrm{B}$ fraction oscillates around $50-60 \%$ of the total sample, although there are some marked deviations. 
For example, some layers of éboulis secs (openwork rubble) are composed of as much as $75 \% \mathrm{~A}$ fraction and that is dominated by quite large fragments; compare samples AP 3-3, 3-6, 10-15, and 6-10 on Figs. 2 and 5 . In contrast, some strata of fresh, unweathered éboulis have relatively little A + B fraction, as little as $30-35 \%$ in AP 5-3 through 5-5 and in these cases the rock fraction is composed of relatively small limestone fragments (see Fig. 5).

Role of Freeze-Thaw Action. It has been generally considered that the size and abundance of rock fragments in the $A+B$ fraction of such rockshelter sediments are a direct function of the intensity of frost shattering of the bedrock walls of the shelter (Bonifay, 1956, 1962). However, recent experiments on frost shattering of limestones have raised some serious doubts about such interpretations (Guillien and Lautridou, 1970; Coutard et al., 1970). These experiments exposed solid blocks of different kinds of limestones to repeated cycles of freeze and thaw under different conditions such as, sudden temperature drop, gradual temperature drop; freezing at $-5,-15$, and $-30^{\circ} \mathrm{C}$; and different moisture conditions.

In summary, these experiments show that smaller fragments will be produced by

i. more freeze-thaw cycles

ii. greater intensity of freezing

iii. greater degree of saturation of the rock.

And, a greater quantity of debris per freeze-thaw cycle will, in general, be produced by

i. greater intensity of frost

ii. greater degree of saturation of the rock.

Thus, the size and abundance of frost debris is a complicated function of time (number of freeze-thaw cycles), temperature (intensity of frost), and moisture (degree of saturation), with the overall result that, for any given limestone, the size of the resulting debris is inversely proportional, and the quantity of debris directly proportional, to each of these factors. Unfortunately it is impossible to evaluate the effect of each of these factors separately in the absence of independent information about one or more of them. (See Farrand, in press, for further discussion.)

With these experimental considerations in mind, one can examine the particlesize distribution of the Abri Pataud éboulis (Figs. 2 and 5). With the exception of the éboulis secs and the heavily weathered layers, the size distributions of the great majority of the Pataud éboulis parallel quite well the size distributions of the experimental frost debris, especially that of calcarenites (Coutard et al., 1970) apparently similar to the Abri Pataud bedrock. The histograms in Fig. 5 show the size distribution of the éboulis to be polymodal. At least two modes are evident in nearly all the histograms, and in many of them three distinct modes can be seen, for example in samples AP 5-1, 5-2, 5-6, 5-8, 12-11, $10-16,10-18,10-21,10-22,10-23,6-3$, 6-7, and 6-11. These modes fall into the following size classes: $64-16 \mathrm{~mm}, 8-4$ $\mathrm{mm}$, and $0.250-0.125 \mathrm{~mm}$. The smallest of these modes is in the $\mathrm{C}$ fractions of the samples and corresponds to the principal size of the sandy particles constituting the local bedrock, as well as to the median size of the Vézère river sand (compare Fig. 8B). Both of the larger modes are composed of fragments of the local bedrock, and both fall into the range of sizes obtained in the freezethaw experiments mentioned.

However, the largest rock fragments, those between the 60 and $100 \mathrm{~mm}$, are perhaps not the direct products of frost activity at all. Among the Abri Pataud samples, those with a mode near $100 \mathrm{~mm}$ are found in beds of éboulis secs (openwork rubble), with few exceptions. Fur- 
thermore, most of éboulis secs are found in association with prominent rockfalls which are represented by huge blocks of limestone generally one to several meters in length. The weaker portions of these blocks undoubtedly shattered upon impact, and that shattering-not frost action-produced the coarse éboulis secs. It would be unrealistic to attribute such a coarse layer to frost action, although the successive roof collapses were certainly the ultimate result of the progressive undercutting of the rockshelter overhang during previous frost activity.

Therefore, it appears that the Abri Pataud éboulis can be explained as follows: (i) the coarsest mode, $>16 \mathrm{~mm}$, appears to be largely the result of shattering of roof blocks as they collapse, although there probably is some contribution to this mode by freeze-thaw activity, (ii) the two finer modes coincide exactly with the granulometric results of the freeze-thaw experiments cited previously, and (iii) the finest mode, 0.250 $0.125 \mathrm{~mm}$ is mainly the result of the reduction of the bedrock to its ultimate components by freeze-thaw activity, but it has been augmented to a greater or lesser degree by a windblown contribution from the floodplain, as discussed previously under the heading of "Heavy Minerals."

The majority of the samples contain both of the coarse modes; 45 of 59 samples contain the $>16 \mathrm{~mm}$ mode, and 33 samples have a distinct mode in the 4- to 2-mm interval, while seven or eight others have a more diffuse mode in this interval. With the exception of nine samples with only the very coarse ( $>16 \mathrm{~mm}$ ) mode (éboulis secs) and three samples with only the sand-sized mode (weathered horizons), all the samples above AP 3-6 and below AP 10-10 are quite similar. Between the horizons of those two samples just mentioned, however, the character of the sediment tends to be different. There the 4- to $2-\mathrm{mm}$ mode, which is strongly correlated with frost activity according to the experimental results, is lacking in most samples, and there is commonly a greater percentage of fine fraction than coarse fraction, especially in the AP 12 series. The reduced importance of the 4- to 2 -mm mode must mean a reduction in frost activity during the time represented by those beds. The increase in the fine mode appears to be primarily due to an increase in the windblown component, and this is confirmed by heavy mineral studies.

Therefore, from the granulometric analysis one can conclude that the time from the beginning of sediment accumulation in the Abri Pataud until the close of Eboulis 5/6 was a period of frequent roof collapses and rather vigorous frost action. The abundance of large limestone blocks in the Aurignacian layers and the occurrence of seven beds of éboulis secs constitute the prime evidence for this conclusion. This was followed by a time of lessened frost activity during the accumulation of the sediments of Level 5 through Eboulis 3/4:Red. Several enormous roof falls occurred during this period, apparently preceded by extensive undercutting by frost. This was also a time of considerable eolian activity and, as we shall see, of two intervals of weathering. Beginning with Eboulis 3/4: Yellow frost action set in once more with vigor, and judging from the smaller mean size of frost spalls one can conclude that the frost action was somewhat stronger than during the earlier periods represented at the Abri Pataud. Moreover, there were fewer roof falls, and only three beds of éboulis secs were sampled in this interval.

Granulometry of the Fine Fraction. Among the primary features of the $\mathrm{C}$ fraction, the median grain size and the degree of sorting show a few interesting variations. The Trask coefficient of sorting (Fig. 2), with one or two exceptions, remains constant in the range $2.0-2.5$, i.e., moderately well sorted. The median 
grain size also is rather constant at or somewhat less than $0.2 \mathrm{~mm}$. These values are exactly those found for decalcified samples of the local bedrock (Fig. 8A and $8 \mathrm{~B}$ ), and they form one of the arguments for the hypothesis that much of the sedimentary matrix came from the disintegration of the bedrock. On the other hand, Eboulis 3/4:Red is much finer and more poorly sorted. Other characteristics of this stratum, however, indicate that we are dealing with a weathered horizon. The cumulative curves of decalcified sediment of the AP 17 series (Fig. 8A) show clearly the smaller median and the poorer sorting of the uppermost three weathered samples (AP 17-1, 2, and 3) relative to the lower two relatively unweathered samples. The latter have curves identical to those of decalcified bedrock (Fig. 8B), if one substracts the clay content (the dashed curve in Fig. 8A). Moreover, all the curves of the AP 17 series are dissimilar to those of the Vézère sand (Fig. 8B).

Travertine Concretion. The final characteristic of the primary sediment to be discussed is the presence of travertine concretion on the faces of certain rock fragments. Its abundance varies considerably (Fig. 2), and its intensity varies from stratum to stratum. In general where the concretion is very abundant, i.e., where it is present on $50 \%$ or more of the fragments (by weight), it is also strongly developed. Travertine concretion is particularly abundant in four different levels: the surface of Level 2 (AP 5-6), in Eboulis 2/3 (AP 2-5), just above and just below Level 11 (AP 10-23 and 6-1), and in Basal Eboulis (AP 6-9). Throughout the rest of the section the abundance of travertine concretion remains, in general, below $20 \%$, and in a few layers it is absent altogether.

The paleoclimatic interpretation of travertine concretion in this climatic region rests on the assumption that moisture is necessary for the solution and translocation of the $\mathrm{CaCO}_{3}$ from the limestone into superficial cracks where it is precipitated by evaporation. Accordingly, an increase in the abundance of concretions is interpreted as being produced by an increase in available moisture.

\section{Modification of the Primary Sediments}

Some of the original sediments have undergone modification since the time of deposition, and these modifications can be measured in terms of rounding, porosity, and soil concretion in the rock fraction, and calcimetry, $\mathrm{pH}$, and clay minerals in the $\mathrm{C}$ fraction.

Rounding and Porosity. 'These parameters must be considered together. The rock fragments are very angular when first formed by freeze-thaw activity, but they may become more and more rounded as the result of mechanical wear or chemical solution. Rounding due to mechanical wear can be distinguished from that due to solution by means of simultaneous observations on the porosity of the fragments. High roundness together with low porosity similar to that of the local bedrock indicates that physical abrasion was the cause of the roundness. In contrast high roundness and high porosity occurring together point to chemical weathering that attacked the intergranular cement of the rock at the same time as it attacked the external corners.

In the Abri Pataud no stratum contains a very great number of well-rounded fragments; most samples contain roughly $50 \%$ angular and subangular fragments and $50 \%$ subrounded to rounded. Two levels are, however, dominated by subrounded and rounded fragments, one is the Basal Eboulis and the other is Eboulis $3 / 4$ :Red through Level 5 complex. The two lowermost samples of the basal éboulis (AP 6-10 and 6-11) have about $70 \%$ of their fragments more rounded than angular. These fragments, moreover, have a relatively high porosity indi- 
cating that they have been subject to considerable solution. This solution apparently resulted from the concentration of groundwater flow at and near the bedrock floor of the abri. The lowermost $10-20 \mathrm{~cm}$ of the Basal Eboulis are tightly cemented in a thick layer of stalagmitic travertine, which is additional evidence of the presence of groundwater.

Except for the uppermost level of Eboulis 3/4:Red (which' has very few rock fragments at all) the percentage of rounded and subrounded fragments remains constantly at 50-90\% throughout the central part of the section, down to and including the very top of Eboulis 5/6 (AP 12-11). In these same layers are found the highest porosity values, although the porosity is not as consistently high as is the roundness. The porosity is nearly $10 \%$ in Eboulis $3 / 4$ :Red, it drops to average values in Level 4 and quite low values in Eboulis 4/5; and then rises again to about $9 \%$ in the top of Level 5 and $8 \%$ in the very top of Eboulis 5/6. Here again as in the Basal Eboulis, relatively high roundness and high porosity occur together, suggesting that solution of the limestone fragments has been the common cause.

No stratum in the Abri Pataud seems to have undergone mechanical rounding in the absence of chemical solution, although this phenomenon is known from some other Dordogne rockshelters in which well rounded, low-porosity eboulis (called éboulis concassés) are attributed to grinding during cryoturbation.

Soil Carbonate. Concretionary soil carbonate is evident in four horizons in the Abri Pataud. In the two uppermost samples (AP 5-1 and 5-2) this carbonate is certainly related to the modern soil currently developing on the éboulis. In these samples $60-75 \%$ of the fragments (by weight) are partially coated with soil carbonate. This is a greater abundance than in any bed within the abri proper, but it is comparable to the development of soil carbonate in certain layers on the talus slope in front of the abri (AP 14 series, see Fig. 2).

A major concentration of soil concretions begins in Eboulis 3/4:Red and builds to a maximum in the underlying Level 4. As we have seen above, Eboulis $3 / 4:$ Red is rich in clay, and contains rounded, porous rock fragments that are few in number. With the presence of these indicators of weathering it is not surprising to find a concentration of soil carbonate at the base of this layer as another indication of pedogenesis.

Another strong peak, in reality a double peak, of soil carbonate occurs in Level 5 . Once again, other characteristics of weathering, such as the dominance of the fine fraction, relatively high roundness and high porosity, correlate with the soil concretions to indicate that we are dealing with another weathered horizon. Moreover, all of these parameters show a greater intensity of weathering at the top and at the base of Level 5 and a distinct interruption at the level of samples AP 12-7 and 12-8.

Consideration of soil carbonate concretions leads us directly to the subject of calcium carbonate content in general. The $\mathrm{CaCO}_{3}$-equivalent has been determined for the $\mathrm{C}$ fraction of all the samples, as explained previously, and we find that the $C$ fraction of apparently unweathered éboulis contains from 60 to $90 \%$ of material soluble in $\mathrm{HCl}$. The decreases in $\mathrm{CaCO}_{3}$-content are, once more, indications of weathering of the eboulis after its formation. $\mathrm{CaCO}_{3}$ is among the first components of the sediment matrix to be removed by groundwater leaching. No further remarks are necessary concerning Eboulis 3/4:Red and Level 5 in which we have already noted numerous other indices of weathering. Moreover, we can note in passing that in both of these cases where one finds a notable decrease in $\mathrm{CaCO}_{3}$ content, one also finds strong indications of soil carbonate con- 
cretions in the immediately subjacent strata. Eboulis 10/11 and Level 11, on the other hand, do not show obvious indications of weathering other than the low $\mathrm{CaCO}_{3}$ values, but they are not altogether lacking in such evidence. In the case of Level 11, sample AP 16-2 shows only $40 \% \mathrm{CaCO}_{3}$-equivalent and the next lower sample, AP 16-3, contains soil carbonate that, although not heavy, is evidence of the downward movement of the carbonate leached from the upper part of Level 11. In Eboulis 10/11 no soil carbonate was found, but the heavy mineral analysis demonstrates that a considerable amount of the matrix of Eboulis 10/11: Wash came from the Vézère floodplain. In fact, Eboulis 10/11: Wash contains the greatest amount of heavy minerals of all the samples analyzed, 10 parts/thousand, a fact that undoubtedly explains the strong brown color of this stratum. The inference that one can draw from Eboulis $10 / 11$ : Wash is that it represents a relatively mild, but brief episode in which sedimentation within the abri slowed considerably or eolian activity on the floodplain increased markedly. The decrease in $\mathrm{CaCO}_{3}$ may be attributed either to leaching of the matrix during this relatively stable period or to the influx of a great amount of carbonate-poor Vézère sand. The heavy minerals support the latter conclusion. This interval of weathering or stability as seen at the Abri Pataud is not a major one, but it provides some support for regional correlation of climatic intervals (Farrand, in press).

Clay Minerals. Clay mineral studies were useful at the Abri Pataud as a general guide to postdepositional alteration of the sediments. As mentioned earlier, montmorillonite is the least stable clay mineral species under the present climate of temperate Europe. In the Abri Pataud one finds the percentage of montmorillonite remains relatively high and constant, at about 40 or $50 \%$, both above and below the major weathered complex of Eboulis 3/4:Red through Level 5. In that weathered complex, however, montmorillonite drops to 20 or $30 \%$, thus furnishing another index of weathering in those strata. Unfortunately, the determination of abundance of the various clay minerals is semiquantitative at best, and it would not be wise to interpret the percentages shown on Fig. 2 to any greater extent.

\section{PALEOCLIMATOLOGY OF THE ABRI PATAUD SEDIMENTS}

In review, we have seen that a number of the sedimentological parameters observed in Abri Pataud sediment can give certain indications of the climate under which the sediments were developing. Variations in the abundance of limestone fragments in the A + B fraction suggests fluctuations in the intensity of freezethaw activity. On the other hand, the amount of fine clay (less than $2 \mu \mathrm{m}$ ) must be a function of breakdown during weathering because such clay is not abundant either in the parent bedrock or in the floodplain sands. Rounding and porosity fluctuate in parallel fashion in the Abri Pataud; increases in both parameters suggest chemical weathering under relatively moist conditions. The abundance of travertine concretions is also an index of the quantity of moisture available. Decreases in the $\mathrm{CaCO}_{3}$-equivalent and concomitant presence of soil carbonate concretions indicate solution weathering, and therefore, relatively moist and mild conditions. Variations in clay-mineral abundance, especially decrease in montmorillonite, are indicative of chemical weathering requiring relatively mild and moist conditions. Heavy minerals, on the other hand, give only indirect help in establishing paleoclimate. In the case of the Abri Pataud, more heavy minerals of the Vézère type indicate a greater eolian influence on abri 
sedimentation relative to éboulis sedimentation from the bedrock.

By combining these various parameters one can establish a paleoclimatic sequence for the Abri Pataud. The following characterizations are based especially on the parameters listed in parentheses.

A. Eboulis 11/12 through Basal Eboulis: Cold episode with fluctuating humidity. (Abundant, mostly angular A fraction of intermediate porosity; two or three peaks of travertine abundance; high $\mathrm{CaCO}_{3}$ values; intermediate to high abundance of montmorillonite.)

B. Eboulis 10/11 through Level 11: Brief moist and relatively mild interval, perhaps double, of incipient pedogenesis and increased eolian activity. (A fraction abundant and angular; low porosity; increased amount of travertine; low $\mathrm{CaCO}_{3}$ equivalent; soil carbonate concretions below Level 11; very abundant Vézère heavy minerals in Eboulis 10/11:Wash.)

C. Eboulis 5/6 through Level 10: Cold and somewhat moist episode including numerous small roof collapses; period of major increase in size of the abri. (Abundant, rather angular A fraction of intermediate to relatively high porosity; moderate amount of travertine; high $\mathrm{CaCO}_{3}$.)

D. Level 5: Prolonged warm, moist pedogenetic interval, apparently double, with marked eolian influence. (Greatly reduced $\mathrm{A}$ fraction and some increase in fine clay; moderately to well rounded; high porosity; intermediate to low $\mathrm{CaCO}_{3}$-equivalent and abundant soil carbonate concretions; intermediate to low montmorillonite, very abundant Vézère heavy minerals.)

E. Level 4 and Eboulis 4/5: Brief cool, somewhat moist episode, colder in Eboulis $4 / 5$, ameliorating into Level 4; includes a major roof collapse. (Moderately abundant A fraction, decreasing upward; low to intermediate porosity, increasing upward; moderately well rounded; intermediate $\mathrm{CaCO}_{3}$ values; rather low montmorillonite.)
G. Level 3 and Eboulis 3/4:Yellow: Cold and dry with major roof collapse. (Abundant coarse, angular A fraction of low porosity; very little travertine; high montmorillonite.)

H. Soil above Level 3: Brief mild episode with incipient pedogenesis. (Reduced A fraction and increased silt plus clay; slight decrease in $\mathrm{CaCO}_{3}$; definite decrease in montmorillonite.)

I. Eboulis 0/1 through Eboulis 2/3: Cold, somewhat moist episode. (Moderately fine to coarse angular éboulis of low porosity; moderately abundant $\mathrm{CaCO}_{3}$; moderate to great amount of travertine; high montmorillonite.)

These paleoclimatic interpretations are summarized in Table 1 which shows the relationships with cultural designations and radiocarbon dates.

\section{CLOSING STATEMENT}

The purpose of this article has been to present concepts and techniques currently being utilized in the sedimentological study of prehistoric sites located in rockshelters and caves. As stated previously, these techniques are being widely used in the Old World, but they are relatively unknown in the Americas, largely because of the language barrier. The Abri Pataud has been used as an example of a typical site situated in western Europe under a temperate, frost climate. The components considered important in the study of such a site are the coarse, angular rock fragments (éboulis) resulting from the breakdown of the enclosing bedrock, the eolian sediments blown into the site from the adjacent floodplain, and to some extent the occupational debris left behind by prehistoric man. Frost action has been considered as a major contributor to the coarse fraction, and the relatively unknown role of spalling due to wetting and drying has been discussed. Moreover, it is thought that the large limestone blocks up to several meters across and the openwork éboulis secs are due primarily to collapse of the over- 
hanging brow, which is the indirect result of centuries of undercutting by frost and solution.

The techniques utilized are largely those with which the sedimentologist is already familiar, but adapted to the special conditions of such a site. In addition, there is a major emphasis on granulometry and shape studies of the coarse fraction up to $100 \mathrm{~mm}$ diam. Study of such coarse materials requires collection of samples up to $15-20 \mathrm{~kg}$ in order to assure a statistically valid sample size.

The results of such a study can be utilized in two different ways. In the first place, certain paleoenvironmental interpretations can be made, and these can shed light on the habitat of the prehistoric men that lived in the area. These conclusions can lead to answers to questions about the effect of climatic change upon cultural evolution, for example. On the other hand, the study of a number of different sites in a given region can lead to a means of correlation among the sites on the basis of regional climatic changes recognized in the sediments. However, caution must be exercised in drawing regional conclusions from the study of a single site. The role of the Abri Pataud in the interpretation of regional climatic and chronological sequences is discussed elsewhere (Farrand, in press), and for a comprehensive study in this area one can consult Laville (1964, 1971).

Finally it must be added that some of the techniques employed here are no longer pertinent when one moves to another climatic zone, and other techniques become important. For example, in extending such studies to the semiarid coastal Near East I have found that the role of frost action, so important in western Europe, becomes negligible in many cases (Farrand, 1972). Thus, those interpretations used in this paper based on the size and abundance of frost spalls and frost blocks are eliminated. This observation brings us back to the very im. portant conclusion, emphasized by many others before me, that in the study of rockshelters and caves we are involved in the study of very specialized niches. Each site must be considered as a separate entity with its sediment accumulation being controlled by numerous variables, the combination of which may not be found in any other site. By extension, the same sorts of variations found in sites under different climatic regimes may not be amenable to the same interpretation. Only the generalizations drawn from the application of these techniques to a great number of sites can lead to valid regional conclusions.

Finally, one reviewer has pointed out that the variations in the parameters reported here are small and in some cases hardly beyond the range of variation in the parent rock. Although this tends to be true in some cases, the variations measured are consistent from place to place in the site and, therefore, believed to be real variations, worthy of detailed study. Weathering is a gradual, progressive phenomenon, and that which we observe in such rockshelter sediments commonly records only the initial stages of the weathering process.

\section{ACKNOWLEDGMENTS}

The writer is most grateful to H. L. Movius, Jr., who encouraged him to undertake this kind of sedimentological study, and who made available all the resources, material, and information of the Abri Pataud Excavations. I wish also to express my gratitude to Mrs. John P. Miller who made available the notebooks of her late husband who had begun the sedimentological study of the Abri Pataud in 1958.

Numerous French colleagues have been especially helpful in giving good counsel and in helping with certain analyses of the sediments. Eugène Bonifay introduced me to his methods of cave sediment analysis. Messrs. $H$, de Lumley and $H$. Laville guided me on visits to numerous other cave sites in southern France. Madame Mireille Ters very kindly provided the heavy mineral analyses. Professor Georges Millot graciously provided laboratory facilities in Strasbourg, and his assistants, Mlle Hélène Paquet 
and M. Güröl Ataman, kindly provided the clay mineral and chemical analyses, respectively.

Finally, and most importantly, the entire study would certainly not have been done without the support in the form of a Postdoctoral Fellowship to the writer, provided by the Air Force Office of Scientific Research and the National Academy of Sciences in the academic year 1963-1964.

\section{REFERENCES}

Bonifay, E. (1956). Les sédiment détritiques grossiers dans les remplissages des grottes. L'Anthropologie, 1956, no. 5-6, 447-461, $194 \mathrm{pp}$.

Bonifay, E. (1962). Les terrains quaternaires dans le sud-est de la France. Delmas, Bordeaux.

Bordes, F. (1972). "A Tale of Two Caves." Harper and Row, New York, 169 pp.

Brothwell, D. and Higgs, E. (1970). "Science in Archaeology." Rev. ed., Praeger Publishers, New York, 720 pp.

Brunnacker, K. and Streit, R. (1967). Neuere Gesichtspunkte zur Untersuchung von HöhlenSedimenten. Jahresheft für karst und Höhlenkunde, Heft 7, vol. xviii, 29-44.

Butzer, K. W. (1971). "Environment and Archeology." 2nd ed., Aldine-Atherton, Chicago, 703 pp.

Coutard, J. P. et al. (1970). Gélifraction expérimentale des calcaires de la campagne de Caen; comparaison avec quelques dépôts périglacaires de cette région. Centre de Géomorphologie, CNRS Caen, Bull. 6, 7-44.

Escalon De Fonton, M. (1971). Stratigraphies, effondrements, climatologie des gisements préhistoriques du S de la France, du Würm III à l'Holocène. Association Française pour l'Etude du Quaternaire, Bulletin no. 29 (1971-4), 199-207.

Farrand, W. R. (1972). Geological correlation of prehistoric sites in the Levant. In "The Origin of Homo Sapiens" (F. Bordes, Ed.), UNESCO, Paris, pp. 227-235.

Farrand, W. R. (In press). The geology of the Abri Pataud (Les Eyzies). In "The Abri Pataud" (H. L. Movius, Jr., Ed.), Papers of the Peabody Museum of Archaeology and Ethnology, Harvard University.
Folk, R. L. (1968). Petrology of Sedimentary

Rocks. Hemphill's, Austin., 170 pp.

Guillien, Y. and Lautridou, J. P. (1970). Recherches de gélifraction expérimentale du Centre de Géomorphologie. I-Calcaires des Charentes. Centre de Géomorphologie, CNRS Caen, Bull. 5, pp. 1-45.

Klingebiel, A. and Latouche, C. (1962). Etude cristallographique des illites, dans les séries éocènes du Bordelais. C. R. Acad. Sci. Paris, Tome 262, pp. 142-144.

Lais, R. (1941). Ueber Höhlensedimente. Quartaer, Vol. III, pp. 56-108.

Laville, H. (1964). Recherches sédimentologiques sur la paléoclimatologie du Würmien récent en Périgord. L'Anthropologie, Tome 68, No. 1-2 and 3-4, pp. 1-48 and 219-252.

Laville, H. (1971). Paléoclimatologie du Würm ancien en Périgord: données sédimentologiques. In "Etudes sur le quaternaire dans le Monde." (M. Ters, Ed.), pp. 513-518, Proceedings, Union Internationale pour l'Etude du Quaternaire, VIII Congress, Paris.

Lumley, H. de. (1969). Le Paléolithique inférieur et moyen du Midi méditerranéen dans son cadre géologique. Tome I, LigurieProvence. Vth supplement to Gallia Préhistoire. Editions du CNRS, Paris, 463 pp.

Millot, G. (1962). Géologie des argiles. Masson et Cie, Paris, 499 pp.

Miskovsky, J. C. (1971). Le remplissage des grottes et abris au Riss et au Würm dans le sud-est de la France: influence climatique sur l'évolution des dépôts. In "Etudes sur le Quaternaire dans le Monde." (M. Ters, Ed.), pp. 683-687, Proceedings, Union Internationale pour l'Etude du Quaternaire, VIII Congress, Paris.

Movius, H. L., Jr. (1972). Radiocarbon dating of the Upper Palaeolithic sequence at the Abri Pataud, Les Eyzies (Dordogne). In "The Origin of Homo Sapiens." (F. Bordes, Ed.), pp. 253-260, UNESCO, Paris.

Schmid, E. (1958). Höhlenforschung und Sedimentanalyse. Basel: Schriften des Institutes für Ur- und Frühgeschichte der Schweiz, No. $13,186 \mathrm{pp}$.

Vertes, L. (1959). Untersuchungen an Höhlensedimenten-Methoden und Ergebnisse. Budapest: Regeszeti Füzetek, Ser. II, 7, 176 pp. 